BMJ Open Diabetes Research \& Care

\title{
Monitoring for proteinuria in patients with type 2 diabetes mellitus
}

\author{
Huifang Liang, ${ }^{1}$ Caroline Kennedy, ${ }^{2}$ Sudhakar Manne, ${ }^{3}$ Jennifer Hsiang-Ling Lin, ${ }^{3}$ \\ Paul Dolin ${ }^{4}$
}

To cite: Liang $\mathrm{H}$, Kennedy $\mathrm{C}$, Manne S, et al. Monitoring for proteinuria in patients with type 2 diabetes mellitus. BMJ Open Diabetes Research and Care 2015;3:e000071. doi:10.1136/bmjdrc-2014000071

\section{- Additional material is} available. To view please visit the journal (http://dx.doi.org/ 10.1136/bmjdrc-2014000071)

Received 20 November 2014 Revised 27 January 2015 Accepted 3 February 2015

\section{(a) CrossMark}

\section{${ }^{1}$ Department of}

Pharmacoepidemiology, Takeda Development Center Americas, Inc., Deerfield, Illinois, USA

${ }^{2}$ Department of Global Statistics, Takeda Development Centre Europe Ltd., London, UK ${ }^{3}$ Observational Research Analytics, Takeda Development Center Americas, Inc., Deerfield, USA

${ }^{4}$ Department of Pharmacoepidemiology, Takeda Development Centre Europe Ltd., London, UK

Correspondence to Dr Huifang Liang; huifang.liang@takeda.com

\section{ABSTRACT}

Objective: The UK National Institute for Health and Care Excellence (NICE) guideline on diabetes recommends at least annual monitoring of patients with type 2 diabetes mellitus (T2DM) for proteinuria. To date, little has been published on the frequency of proteinuria monitoring in T2DM, and its association with risk factors for renal complications. We aimed to describe proteinuria monitoring in patients with T2DM.

Design: This study identified patients with T2DM aged 40 years or older with the first antidiabetic drug use in 2007-2012 (cohort entry) in the UK Clinical Practice Research Datalink. At least 1 year of registration before and after cohort entry was required. A test was considered undertaken if a medical or laboratory code indicated a urinary albumin or protein test. The percentage of patients with at least one test performed was obtained in 1 year after cohort entry and any time during follow-up. A Cox proportional hazards model was used to estimate the HRs of patients having the first screening test while adjusting for baseline covariates.

Results: 65790 patients (mean age 63.0 years, men $57.5 \%$, mean follow-up 41.0 months) were included, of whom $49707(75.6 \%)$ patients had at least one test in 1 year after antidiabetic drug initiation and 59400 $(90.3 \%)$ had at least one test any time during follow-up. Proteinuria monitoring decreased with time since initiation of antidiabetic drug therapy and with number of treatment changes and was independently associated with age, sex, smoking status, and year of antidiabetic drug initiation. $12.3 \%$ of patients with T2DM tested had a positive proteinuria test for the first screening performed in 1 year after initiation of antidiabetic drug therapy.

Conclusions: The findings suggested suboptimal compliance with the NICE guideline on proteinuria monitoring in patients with T2DM and that level of monitoring appeared to depend on multiple clinical factors.

\section{INTRODUCTION}

Nephropathy is an established complication in patients with type 2 diabetes mellitus (T2DM). Common risk factors for renal disease include older age, men, ${ }^{1}$ ethnic minority status, ${ }^{2}$ cigarette smoking, ${ }^{3}$ hypertension, and poor glycemic control. ${ }^{4}$ The UK

\section{Key messages}

- In a nationally representative type 2 diabetes mellitus (T2DM) patient population aged 40 years or older, proteinuria monitoring in $75.6 \%$ of patients was compliant with the UK National Institute for Health and Care Excellence (NICE) guideline.

- Proteinuria monitoring decreased with time since start of diabetic drug therapy and with number of treatment changes and was independently associated with age, sex, smoking status, and year of antidiabetic drug initiation.

- In total, $12.3 \%$ of patients with T2DM tested in the first year after antidiabetic drug initiation had the first proteinuria test positive.

National Institute for Health and Care Excellence (NICE) guideline on diabetes recommends at least annual monitoring of patients with T2DM for proteinuria. ${ }^{5}$

Proteinuria may be monitored qualitatively, using a dipstick method, ${ }^{6}$ or quantitatively by assessing $24 \mathrm{~h}$ or a spot urine for urinary protein or albumin. ${ }^{7}$ Owing to different detection limits and different false-positive and false-negative rates in albuminuria test methods, the NICE guideline recommends repeating a urinary test if an abnormal albumin: creatinine ratio is obtained at each of the next two clinic visits but within a maximum of 3-4 months. ${ }^{7}$ Limited publications are available on the frequency of proteinuria, proteinuria monitoring, and its associations with renal disease risk factors in patients with T2DM. ${ }^{8}$

The purposes of this study were to (1) assess the frequency of proteinuria monitoring in patients with T2DM; (2) understand the association between proteinuria monitoring and renal disease risk factors in patients with T2DM, and whether the frequency of proteinuria testing varies by age, sex, smoking status, history of hypertension, renal complications, and antidiabetic drug therapy; and (3) evaluate the prevalence of proteinuria in patients with T2DM in the UK. 


\section{RESEARCH DESIGN AND METHODS}

\section{Study design}

A retrospective cohort study was conducted using the UK Clinical Practice Research Datalink GP OnLine Data (CPRD GOLD, formerly known as General Practice Research Database, or GPRD). As an electronic medical record database, the CPRD includes patient and practice information, medical events, prescribed therapies, and information on other areas of care such as tests, lifestyle factors, immunizations, and specialty consultation notes from referrals. It has been available since 1987 and represents over $9 \%$ of the UK population as of 29 July 2013.

\section{Study population}

Patients who initiated antidiabetic drug therapy during 2007-2012 in the CPRD formed the study population. The date of the first ever antidiabetic drug prescription was defined as the cohort entry date (CED).

Patients were eligible if they (1) came from a general practice that was 'up to research standard' on CED, (2) had 'Acceptable Quality Standard' data, including known year of birth and sex, (3) were continuously with a general practice for at least 1 year before and after the CED, and (4) were at least 40 years old on the CED. The rationale of this age restriction was to minimize the possibility of patients with type 1 diabetes to be included in this study.

Patients with a diagnosis of type 1 diabetes mellitus, gestational diabetes mellitus, diabetes insipidus, or secondary or other forms of diabetes mellitus, including nutritional, genetic, postsurgical, and drug-induced or chemical-induced diabetes, at any time during the study period were excluded.

All information for the study population was de-identified, and no patient enrolment or medical chart review was involved. This study protocol was approved by the CPRD Independent Scientific Advisory Committee (ISAC) for Medicines \& Healthcare products Regulatory Agency (MHRA) Database Research before study conduct.

\section{Exposure, outcomes, and covariates}

The primary outcomes were the percentage of patients who had at least one test within 1 year after CED, and the time to the first test for proteinuria, microalbuminuria, or albuminuria (hereafter collectively termed proteinuria) after CED or during specific substratum of follow-up time (1, 2, 3, 4, and $\geq 5$ years after the CED). A test for urinary albumin or urinary protein was considered undertaken if a medical code in a clinical or test record or an entity type in a test record indicated that a test was performed. Follow-up period ran from CED to the earlier date of proteinuria screening test or end of the patient medical record in CPRD, which could be patient death, or the transfer out of the general practice, or the end of the study period (29 July 2013).

The secondary outcomes were the percentage of first test results (performed in year after CED) that were positive, negative, or unknown for proteinuria and the percentage of second test results that were positive, negative, or unknown for proteinuria between 14 and 90 days after the first screening test. The 13-day window from the first test was assumed to be the time required to obtain the results of the first test and any laboratory tests associated with the first test. The 14-90-day window from the first test was assumed to be the time required to get the second tests performed. A test result was considered positive if there was: (1) a Medcode in the clinical or test record indicating a positive result; (2) a Medcode in the clinical or test record indicating a diagnosis of albuminuria, proteinuria, nephrotic syndrome, or diabetic nephropathy; (3) a Medcode-Enttype pair in the test record indicating a positive, elevated, or abnormal result; (4) a Qualifier in the test record indicating a positive, elevated, or abnormal result; or (5) a laboratory value above the threshold criteria for albuminuria/proteinuria (see table 1). A test result was considered negative (normal) if there was: (1) a Medcode in the clinical or test record indicating a negative result; (2) a Medcode-Enttype pair in the test record indicating a negative result; (3) a Qualifier in the test record indicating a negative, normal, or trace result; or (4) a laboratory value below the threshold criteria for albuminuria/ proteinuria (see table 1). A test was considered unknown if there was: (1) no Medcode, Qualifier, or laboratory value indicating the test result; (2) a mismatched Medcode-Enttype pair (eg, Medcode=urinary albumin test, Enttype=urinary urea test); (3) a laboratory unit for a Medcode-Enttype pair not normally used for urinary albumin or protein testing; or (4) a laboratory

Table 1 The threshold criteria for albuminuria or proteinuria

\begin{tabular}{|c|c|c|c|c|c|c|c|}
\hline \multirow[b]{3}{*}{ Urinary test type } & \multirow[b]{3}{*}{ Category } & \multicolumn{2}{|c|}{ Excretion rate } & \multicolumn{4}{|l|}{ Spot urine } \\
\hline & & \multirow[b]{2}{*}{$\mathrm{mg} / 24 \mathrm{~h}^{9}$} & \multirow[b]{2}{*}{$\mu \mathrm{g} / \mathrm{min}^{9}$} & \multirow[b]{2}{*}{ Concentration (mg/L) } & \multicolumn{2}{|c|}{$\begin{array}{l}\text { Albumin or protein } \\
\text { to creatinine ratio }\end{array}$} & \multirow[b]{2}{*}{ Dipstick $^{9}$} \\
\hline & & & & & $\mathrm{mg} / \mathrm{mmol}^{9}$ & $\mathrm{mg} / \mathrm{g}^{\star 9}$ & \\
\hline \multirow[t]{2}{*}{ Albumin } & Normal & $<30$ & $<20$ & $<20^{10}$ & $<3$ & $<30$ & NA \\
\hline & Abnormal & $\geq 30$ & $\geq 20$ & $\geq 20^{10}$ & $\geq 3$ & $\geq 30$ & NA \\
\hline \multirow[t]{2}{*}{ Protein } & Normal & $<150$ & $\bar{N} A$ & $<150^{11}$ & $<15$ & $<150$ & Negative to trace \\
\hline & Abnormal & $\geq 150$ & NA & $\geq 150^{11}$ & $\geq 15$ & $\geq 150$ & + to ++++ \\
\hline
\end{tabular}


value that exceeded the predefined threshold for valid values. From the conservative side, patients with a positive result and a negative result on the same day were considered to have a positive result. The algorithms to retrieve valid laboratory values and the predefined thresholds for valid values were presented in online supplementary figure S1 and table S1.

All baseline characteristics were considered covariates in this primarily descriptive analysis. They consisted of age at cohort entry, sex, smoking status (based on most recent smoking status prior to CED), history of hypertension (based on a Read code diagnosis of hypertension any time before the CED), year of an antidiabetic drug initiation, and history of diabetic renal complications (defined as a diagnosis of albuminuria, proteinuria, diabetic nephropathy, nephrotic syndrome, chronic renal disease, renal failure, dialysis, or renal transplant at any time before CED).

The antidiabetic medications were classified into $\alpha$-glucosidase inhibitors, amylinomimetics, biguanides, dipeptidyl peptidase-4 inhibitors, glucagon-like peptide-1 agonist (aka incretin mimetics), insulins, meglitinides, sodium-glucose cotransporter 2 inhibitors, sulfonylureas (SU), thiazolidinediones (TZDs; pioglitazone or other TZDs), and miscellaneous antidiabetic agents. To describe proteinuria monitoring after antidiabetic drug initiation, several variables were defined using data after CED: (1) time since start of antidiabetic drug therapy, or the duration of treated diabetes. (2) Three antidiabetic drug treatment periods were constructed: the first period ran from the date of antidiabetic drug initiation to the date immediately before the first change in treatment; the second period ran from the date of the first change in therapy to the date immediately before the second change in treatment; and the third treatment period ran from the second change in therapy to the date immediately before the third change in treatment.

The first treatment was considered a monotherapy if only one antidiabetic medication was prescribed within 7 days after CED; otherwise, the first treatment was considered a combination therapy. A combination therapy could be a fixed-dose combination or more than one single agent that were used with an overlap of at least 30 days, except for a fixed-dose combination of insulin (eg, short-term act aspart and long-term act protamine together), which was considered insulin monotherapy. If insulin was used with other non-insulin agent for at least 30 days of overlap, it was considered a combination therapy. The end date of a medication was defined as the last date of the medication prescription plus 60 days. The second treatment could be an add-on therapy or a switch therapy (from one drug class to another). An add-on therapy was defined as a new prescription added to the pre-existing medication with at least 30 days of overlap. A switch therapy was defined as an overlap of 0 to less than 30 days. A change in drug dose only, a switch from a combination therapy to a fixed-dose combination therapy of same drugs, and a switch from one drug to another in same class were not considered a change in therapy.

\section{Statistical analysis}

Baseline characteristics were expressed as means and SDs for continuous variables and as frequencies and percentages for categorical variables. The percentage of patients who had at least one test within 1 year after cohort entry and at any time during follow-up was analyzed by each baseline characteristic. The time to the first proteinuria test was presented as a median and IQR (Q1-Q3) overall as well as stratified by baseline characteristics among those with at least one test during follow-up. A $\chi^{2}$ test (for trend) and a Wilcoxon rank-sum or Kruskal-Wallis test was used to test proportions and the median time to the first test, respectively, for statistical significance $(p<0.05)$ among groups. Sensitivity analysis was performed for patients who did not have a history of diabetic renal complications. Similar analyses were conducted by time since start of antidiabetic drug therapy, antidiabetic treatment periods, and antidiabetic treatment courses (metformin, $\mathrm{SU}$, etc). To remove the impact of variable follow-up time among patients, analyses by treatment periods and treatment courses only included those who had medical records covered at least 1 year after the start of the period or treatment course; and only proteinuria tests that were performed within 1 year after initiation of each treatment period/course were counted. In addition, the substratum analyses were further stratified by a history of diabetic renal complications. Data for treatment periods/courses with at least 500 users were presented.

Among patients with the first test undertaken in 1 year after cohort entry, the percentage of patients with the first test result status (positive, negative, and unknown) was calculated overall as well as by baseline characteristics. In addition, the percentage of these patients with a second test undertaken between 14 and 90 days after the first test and their second test result status were further analyzed.

Finally, a Cox proportional hazards model was used to estimate the HRs of having the first screening test among groups while adjusting for age (40-49 (reference), 50-59, 60-69, 70-79, 80+ years), sex (female (reference), male), smoking status (never-smoker (reference), current smoker, former smoker, and unknown smoking status), history of hypertension (no (reference), yes), year of cohort entry (2007 (reference), 2008, 2009, 2010, 2011, 2012), and history of diabetic renal complications (no (reference), yes). All data were managed and analyzed using SAS software V.9.2 (SAS Institute Inc., Cary, North Carolina, USA).

\section{RESULTS}

A total of 65790 patients were identified who initiated an antidiabetic medication during 2007-2012. The detailed patient attrition is presented in figure 1. 


\begin{tabular}{|c|c|c|}
\hline Patient inclusion or exclusion criteria & $\begin{array}{l}\text { Patients } \\
\text { excluded }\end{array}$ & $\begin{array}{l}\text { Patients } \\
\text { remaining }\end{array}$ \\
\hline Patients who initiated an antidiabetic medication in CPRD* (launch-29Jul2013) & NA & 461,608 \\
\hline \multicolumn{3}{|l|}{ Patients were excluded from above cohort if they } \\
\hline initiated an antidiabetic medication before 01Jan 2007 & 294,601 & 167,007 \\
\hline lacked an acceptable patient flag in the patient file & 9,705 & 157,302 \\
\hline came from general practice not 'Up to research standard' on cohort entry date & 0 & 157,302 \\
\hline had less than one year of CPRD membership before cohort entry date & 54,596 & 102,706 \\
\hline were less than 40 years old at cohort entry date & 15,176 & 87,530 \\
\hline had a diagnosis of type 1 diabetes mellitus at any time & 1,330 & 86,200 \\
\hline had a diagnosis of gestational diabetes at any time & 580 & 85,620 \\
\hline had a diagnosis of secondary diabetes at any time $\dagger$ & 774 & 84,846 \\
\hline had less than one year of follow-up after cohort entry date & 19,056 & 65,790 \\
\hline Final cohort & NA & 65,790 \\
\hline
\end{tabular}

Figure 1 Patient attrition to obtain T2DM cohort who initiated an antidiabetic medication during 2007-2012 in CPRD GOLD.

The average age was 63.0 years (range 40-103, SD 12.0 ), with mean follow-up time of 41.0 months (SD 18.6). Among them, about $60 \%$ were aged 60 years or older (see table 2) and there were more men than women $(57.5 \%$ vs $42.5 \%)$. Over $60 \%$ had ever smoked (current $17.7 \%$ and former smokers $43.3 \%$ ) and $55.4 \%$ had a history of hypertension. Cohort entry peaked in year 2009 and then tapered. In total, $13.2 \%$ of patients had a history of diabetic renal complications on the date of the first ever antidiabetic drug prescription.

In total, $75.6 \%$ of patients had at least one test for proteinuria in 1 year after CED; $90.3 \%$ of patients had at least one test at any time during follow-up (table 2). The median time to the first test was 4.9 months, with the IQR from 1.1 to 11.9 months. The percentage of patients who had at least one test in 1 year after cohort entry increased with age but tapered for those aged 80 or over ( $p$ for trend $<0.0001$ ). Conversely, the percentage of patients who had at least one test in 1 year after cohort entry seemed to decrease with year of cohort entry ( $p$ for trend $<0.0001$ ). When patients with a history of diabetic renal complications were excluded, the percentage of patients who had at least one test followed similar patterns (see online supplementary table S2). No clear trend was identified for the median time to the first test, though $\mathrm{p}$ was significant for all variables except history of hypertension.

When we assessed the monitoring based on the substratum of follow-up time, the percentage of patients who had at least one test for proteinuria during observed year decreased with time since start of antidiabetic drug therapy (from $75.6 \%$ in the first year to $58.7 \%$ in the fifth year, see table 3 ). Notably, the annual test rate (all above $85 \%$ ) seemed to be much higher among those whose treatment period or treatment course lasted for at least 1 year. Although percentage tested decreased with each of antidiabetic drug treatment (1st vs 2nd vs 3rd treatment: $98.5 \%$ vs $93.5 \%$ vs $89.8 \%$ ), there appeared to be no differences between different treatment courses in the same treatment period. When stratified by diabetic renal complications, the first treatment period tended to have the highest percentage of patients with at least one test and the shortest time to the first test (see online supplementary table S3).

In the adjusted Cox proportional hazards model, increasing age, male sex, former smoker were associated with increased HR to receive the first screening test (table 4). Compared with those 40-49 years old, the HR of receiving the first test increased as age increased, peaked at 70-79 years (adjusted HR=1.28, 95\% CI 1.24 to 1.31), and then tapered for those aged 80 years or older. Recent year of antidiabetic drug initiation appeared to be associated with reduced likelihood of receiving the first test. Neither a history of hypertension nor a history of diabetic renal complications was found to be independently associated with the likelihood of receiving the first test.

Among those who had a proteinuria test within 1 year after CED (see online supplementary table S4), the percentages of patients with the first test positive, negative, or unknown were $12.3 \%, 45.9 \%$, and $41.9 \%$, respectively. The percentage of patients with a second positive, negative, or unknown result was $44.9 \%, 68.9 \%$, and $64.7 \%$, respectively, highest among those with the first test positive, negative, and unknown, respectively. The percentage of the first proteinuria test positive seemed to be higher in those with a history of renal complications at cohort entry $(19.4 \%)$, those 80 years or over $(15.9 \%)$, current smokers $(14.1 \%)$, and men $(13.6 \%$; see online supplementary table S5). The percentages of unknown test results appeared to decrease with year of cohort entry, from $43.1 \%$ in 2007 to $40.7 \%$ in 2012 , which might indicate the improvement in quality of laboratory data entry by the general practitioner (GP) across the years.

\section{DISCUSSION}

We observed an annual proteinuria test rate of $75.6 \%$ among patients with T2DM in the first year after antidiabetic drug initiation. The annual test rate decreased with time since start of antidiabetic drug therapy and with number of treatment changes. We also found that proteinuria monitoring during follow-up was 
Table 2 Patient characteristics at baseline and the percentage of patients with at least one test in 1 year after initiation of antidiabetic drug therapy and at any time during follow-up

\begin{tabular}{|c|c|c|c|c|c|c|}
\hline Characteristics & $\begin{array}{l}\text { Number of } \\
\text { patients (\%) }\end{array}$ & $\begin{array}{l}\text { Number of } \\
\text { patients with at } \\
\text { least one test in } \\
1 \text { year after cohort } \\
\text { entry (\%) }\end{array}$ & $\begin{array}{l}p \text { Value } \\
\text { for } \chi^{2} \\
\text { test for } \\
\text { trend }\end{array}$ & $\begin{array}{l}\text { Number of } \\
\text { patients with at } \\
\text { least one test } \\
\text { during any time in } \\
\text { the follow-up (\%) }\end{array}$ & $\begin{array}{l}\text { Time in months to } \\
\text { the first test among } \\
\text { patients with at } \\
\text { least one test } \\
\text { (median, Q1-Q3)* }\end{array}$ & $\begin{array}{l}p \text { Value } \\
\text { for } \\
\text { trend }\end{array}$ \\
\hline $\mathrm{N}$ & $65790(100)$ & 49707 (75.6) & - & 59400 (90.3) & $4.9(1.1-11.9)$ & - \\
\hline \multicolumn{7}{|l|}{ Age (years) } \\
\hline $40-49$ & $9838(15.0)$ & $6836(69.5)$ & $<0.0001$ & 8441 (85.8) & $3.9(0.8-10.1)$ & $<0.0001$ \\
\hline $50-59$ & $16322(24.8)$ & $12127(74.3)$ & & 14668 (89.9) & $3.8(0.7-9.7)$ & \\
\hline $60-69$ & $19493(29.6)$ & $15040(77.2)$ & & 17921 (91.9) & $4.0(0.8-9.7)$ & \\
\hline $70-79$ & $14321(21.7)$ & $11414(79.7)$ & & 13244 (92.5) & $3.9(0.8-9.1)$ & \\
\hline $80+$ & $5816(8.8)$ & $4290(73.8)$ & & $5126(88.1)$ & $4.4(1-10)$ & \\
\hline \multicolumn{7}{|l|}{ Sex } \\
\hline Male & 37822 (57.5) & 28714 (75.9) & 0.8849 & 34321 (90.7) & $3.9(0.8-9.7)$ & 0.0145 \\
\hline Female & 27968 (42.5) & $20993(75.1)$ & & 25079 (89.7) & $4(0.9-9.7)$ & \\
\hline Smoking status & & & 0.0164 & & & \\
\hline Never & 23885 (36.3) & 17905 (75.0) & & 21459 (89.8) & $3.9(0.8-9.7)$ & 0.0003 \\
\hline Current & 11638 (17.7) & 8566 (73.6) & & 10348 (88.9) & $3.9(0.8-9.9)$ & \\
\hline Former & 28498 (43.3) & 21950 (77.0) & & 26081 (91.5) & $4.1(0.8-9.7)$ & \\
\hline Unknown & $1769(2.7)$ & $1286(72.7)$ & & $1512(85.5)$ & $3.1(0.7-8.0)$ & \\
\hline $\begin{array}{l}\text { Year of cohort } \\
\text { entry }\end{array}$ & & & $<0.0001$ & & & $<0.0001$ \\
\hline 2007 & 11959 (18.2) & 9187 (76.8) & & $11288(94.4)$ & $4.2(0.9-10.3)$ & \\
\hline 2008 & 12014 (18.3) & 9287 (77.3) & & 11259 (93.7) & $3.9(0.8-10.0)$ & \\
\hline 2009 & $12658(19.2)$ & 9777 (77.2) & & $11700(92.4)$ & $3.8(0.8-9.6)$ & \\
\hline 2010 & 12306 (18.7) & 9158 (74.4) & & 11043 (89.7) & $4.1(0.9-9.9)$ & \\
\hline 2011 & $11062(16.8)$ & 8066 (72.9) & & 9541 (86.3) & $3.9(0.8-9.6)$ & \\
\hline 2012 & $5791(8.8)$ & 4232 (73.1) & & 4569 (78.9) & $3.5(0.6-8.0)$ & \\
\hline $\begin{array}{l}\text { History of } \\
\text { hypertension }\end{array}$ & & & 0.6154 & & & 0.8910 \\
\hline No & $29324(44.6)$ & $21845(74.5)$ & & 26078 (88.9) & $3.6(0.7-9.4)$ & \\
\hline Yes & 36466 (55.4) & 27862 (76.4) & & 33322 (91.4) & $4.2(0.9-9.9)$ & \\
\hline $\begin{array}{l}\text { History of } \\
\text { nephropathy }\end{array}$ & & & 0.9610 & & & $<0.0001$ \\
\hline No & $57114(86.8)$ & $43062(75.4)$ & & 51461 (90.1) & $3.9(0.8-9.6)$ & \\
\hline Yes & 8676 (13.2) & 6645 (76.6) & & 7939 (91.5) & $4.6(1.0-10.0)$ & \\
\hline
\end{tabular}

*Patients' follow-up time was censored on the date of the first test for proteinuria during follow-up.

†History of diabetic renal complications was defined as a diagnosis of albuminuria, proteinuria, diabetic nephropathy, nephrotic syndrome, chronic renal disease, renal failure, dialysis, or renal transplant at any time before cohort entry date.

independently associated with increasing age, men, former smoker, and year of cohort entry. Of those who were tested, $12.3 \%$ had a positive proteinuria result for the first test performed in 1 year after antidiabetic drug initiation.

The UK NICE guideline recommends that patients with T2DM should be monitored annually for urinary albumin. ${ }^{5}$ In our study, $75.6 \%$ of patients with T2DM had at least one test in 1 year after antidiabetic drug initiation. A similar rate, $80.63 \%,{ }^{12}$ was reported by the Health \& Social Care Information Centre (HSCIC) QOF report for 2011, although our analysis only included patients with T2DM aged 40 years or older who had initiated antidiabetic drug therapy, whereas the QOF report data included both type 1 and type 2 patients on the diabetes register who were 17 years or older. When the proteinuria test at any time during follow-up was counted, the proportion of patients who had a screening test increased to $90.3 \%$.

Our data suggested that the level of proteinuria monitoring in patients with T2DM was suboptimal and well below that recommended by NICE. When the monitoring was assessed based on the substratum of follow-up time, the annual test rate decreased with time since start of antidiabetic drug therapy and with number of treatment changes, which suggested that GPs tended to monitor the patients' renal function more closely shortly after the antidiabetic drug initiation. The test rate was also higher among those whose treatment period or treatment course lasted for at least 1 year. A further exploration revealed that those patients were more likely to be men $(58.3 \%$ vs $55.7 \%)$, former smokers $(44.5 \%$ vs $40.8 \%$ ), and have a history of hypertension $(57.6 \%$ vs $50.5 \%)$ than those who did not (all $\mathrm{p}<0.0001)$. 
Table 3 Number of patients at start of period and the time to the first test among patients with at least one test

\begin{tabular}{|c|c|c|c|}
\hline $\begin{array}{l}\text { Substratum of } \\
\text { follow-up time }\end{array}$ & $\begin{array}{l}\text { Number of patients } \\
\text { at start of period }\end{array}$ & $\begin{array}{l}\text { Number of patients with } \\
\text { at least one test for proteinuria } \\
\text { during } 1 \text { year period }(\%)^{\star}\end{array}$ & $\begin{array}{l}\text { Time in months to the first test } \\
\text { among patients with at least one test in } \\
\text { the } 1 \text { year period (median, Q1-Q3) }\end{array}$ \\
\hline \multicolumn{4}{|c|}{ Time since start of diabetic drug therapy $\dagger$} \\
\hline 0 to $\leq 1$ st year & 65790 & $49707(75.6)$ & $2.9(0.5-6.3)$ \\
\hline$>1$ to $\leq 2$ nd year & 65735 & $43690(66.5)$ & $4.0(1.7-7.1)$ \\
\hline$>2$ to $\leq 3 \mathrm{rd}$ year & 50705 & 32895 (64.9) & $4.1(1.8-7.1)$ \\
\hline$>3$ to $\leq 4$ th year & 36948 & $22848(61.8)$ & $4.1(1.8-7.0)$ \\
\hline$>4$ to $<5$ th year & 23879 & $13993(58.6)$ & $3.8(1.7-6.8)$ \\
\hline \multicolumn{4}{|c|}{ Antidiabetic treatment period $\ddagger$} \\
\hline 1st treatment & 45161 & $44469(98.5)$ & $4.0(0.8-9.5)$ \\
\hline MET & 41269 & 40670 (98.5) & $4.0(0.8-9.5)$ \\
\hline SU & 2506 & 2447 (97.6) & $4.0(0.9-9.6)$ \\
\hline $\mathrm{MET}+\mathrm{SU}$ & 845 & 830 (98.2) & $2.3(0.3-6.9)$ \\
\hline 2nd treatment & 15046 & $14062(93.5)$ & $5.8(2.3-10.6)$ \\
\hline MET+SU & 9511 & 8923 (93.8) & $5.8(2.1-10.6)$ \\
\hline MET+DPP4I & 1945 & 1789 (92.0) & $5.7(2.3-10.8)$ \\
\hline MET+PIO & 968 & $898(92.8)$ & $6.5(2.8-11.5)$ \\
\hline SU & 960 & 902 (94.0) & $5.8(2.4-9.7)$ \\
\hline 3rd treatment & 3986 & 3579 (89.8) & $6.1(2.7-10.6)$ \\
\hline SU+DPP4I & 1261 & 1137 (90.2) & $6.0(2.5-10.6)$ \\
\hline \multicolumn{4}{|c|}{$\begin{array}{l}\text { *Only patients who had at least one test for proteinuria during the specified period were counted. } \\
\text { †Only patients who had at least certain years of antidiabetic drug therapy were counted at start of period assessed. For example, } 23879 \\
\text { patients had at least } 4 \text { years since start of antidiabetic drug therapy. } \\
\text { †Only treatment periods/courses that lasted for at least } 1 \text { year were counted; and only proteinuria tests that were performed within } 1 \text { year after } \\
\text { initiation of each treatment period/course were counted. Data for the most frequently used antidiabetic drug treatment with at least } 500 \text { users } \\
\text { were presented. } \\
\text { DPP4I, dipeptidyl peptidase } 4 \text { inhibitors; MET, metformin; PIO, pioglitazone; SU, sulfonylureas. }\end{array}$} \\
\hline
\end{tabular}

We found that the proportion of patients who had a screening test tapered for those aged 80 years or above, consistent with the report that people over 80 are lower users of outpatient services than those in their $60 \mathrm{~s}$ and $70 \mathrm{~s} .{ }^{13}$ We also found that men were more likely to receive a proteinuria test than women. No literature was identified that compared the prevalence of proteinuria testing between men and women. Smoking is one of the main risk factors for the development of nephropathy. $^{3} 1415$ Our finding of increased monitoring in former smokers was supported by the data from the US National Health and Nutrition Examination Survey (NHANES), which indicates that cigarette smoking is associated with higher healthcare utilization for former smokers than for never-smokers. ${ }^{16}$ Former smokers are more likely than never-smokers to have $\geq 4$ outpatient visits regardless of when they quit. As expected, neither a history of hypertension nor a history of nephropathy was found to be associated with shorter time to the first test. A few studies found that albuminuria reduction by antihypertensive drugs, ACE inhibitors, or angiotensin receptor blockers through inhibition of the rennin-angiotensin-aldosterone system has been associated with renal protection. Some patients with T2DM with a history of hypertension may already have nephropathy. ${ }^{17}$ The GPs can exempt patients with proteinuria from inclusion in the QOF, so-called 'exception reporting'. ${ }^{12}$
We found that among $49707(75.6 \%)$ patients with at least one test performed in 1 year after CED, $12.3 \%$ had proteinuria based on the first test. Considering $13.2 \%$ of 65790 patients with T2DM had a history of nephropathy at CED and $41.9 \%$ of 49707 patients had first test result unknown, our finding that $12.3 \%$ of patients with T2DM had proteinuria was likely to be an underestimate. An exploration of the unknown quantitative laboratory results in the CPRD data set indicated that the unknown result was due to data not entered (missing data, $98.7 \%)$, wrong or missing laboratory units $(1.1 \%)$, unmatched medical code and laboratory entity type $(0.2 \%)$, or outliers $(0.01 \%)$. There are no UK national data on the prevalence of kidney disease in diabetes. Our finding, though underestimated, was quite similar to data from a large randomized clinical trial of patients with T2DM $(n=994),{ }^{19}$ in which at diagnosis of T2DM, $12.8 \%$ had microalbuminuria and $2.1 \%$ had evidence of proteinuria. However, the prevalence of proteinuria and microalbuminuria increased to $14.5 \%$ and $2.5 \%$ at 3 years of follow-up, and $12.6 \%$ and $39.0 \%$ at 15 years of follow-up, respectively. Therefore, prevention of progression of kidney disease in T2DM is very important.

In the UK, diabetes is managed in primary care, with most primary care practices having specialized diabetic care clinics. As NICE guideline recommends at least annual monitoring of renal function and urinary albumin in patients with T2DM and monitoring of 
Table 4 Crude and adjusted HRs of having the first screening test

\begin{tabular}{|c|c|c|c|}
\hline Characteristics & $\begin{array}{l}\text { Number of patients with } \\
\text { at least one test for proteinuria* }\end{array}$ & Crude HR (95\% Cl) & Adjusted HR (95\% Cl)† \\
\hline \multicolumn{4}{|l|}{ Age (years) } \\
\hline $40-49$ & 8441 & Reference & Reference \\
\hline $50-59$ & 14668 & $1.15(1.12$ to 1.18$)$ & $1.14(1.11$ to 1.18$)$ \\
\hline $60-69$ & 17921 & $1.23(1.19$ to 1.26$)$ & 1.21 (1.18 to 1.25$)$ \\
\hline $70-79$ & 13244 & 1.29 (1.26 to 1.33$)$ & $1.28(1.24$ to 1.31$)$ \\
\hline $80+$ & 5126 & 1.07 (1.06 to 1.13$)$ & 1.09 (1.05 to 1.13$)$ \\
\hline \multicolumn{4}{|l|}{ Sex } \\
\hline Female & 25079 & Reference & Reference \\
\hline Male & 34321 & 1.04 (1.03 to 1.06$)$ & 1.04 (1.03 to 1.06$)$ \\
\hline \multicolumn{4}{|l|}{ Smoking status } \\
\hline Never & 21459 & Reference & Reference \\
\hline Current & 10348 & $0.97(0.97$ to 1.00$)$ & $0.98(0.95$ to 1.00$)$ \\
\hline Former & 26081 & 1.06 (1.04 to 1.08$)$ & $1.03(1.01$ to 1.05$)$ \\
\hline Unknown & 1512 & 0.94 (0.89 to 0.99$)$ & 0.95 (0.90 to 1.00$)$ \\
\hline \multicolumn{4}{|c|}{ Year of cohort entry } \\
\hline 2007 & 11288 & Reference & Reference \\
\hline 2008 & 11259 & 1.01 (0.98 to 1.03$)$ & $1.01(0.98$ to 1.04$)$ \\
\hline 2009 & 11700 & 0.99 (0.97 to 1.02$)$ & 0.99 (0.97 to 1.02$)$ \\
\hline 2010 & 11043 & $0.92(0.89$ to 0.94$)$ & 0.92 (0.89 to 0.94$)$ \\
\hline 2011 & 9541 & $0.89(0.85$ to 0.91$)$ & 0.88 (0.85 to 0.92$)$ \\
\hline 2012 & 4569 & 0.88 (0.88 to 0.91$)$ & 0.90 (0.88 to 0.91$)$ \\
\hline \multicolumn{4}{|c|}{ History of hypertension } \\
\hline No & 26078 & Reference & Reference \\
\hline Yes & 33322 & 1.05 (1.03 to 1.06$)$ & 1.01 (0.99 to 1.03$)$ \\
\hline \multicolumn{4}{|c|}{ History of nephropathy $\ddagger$} \\
\hline No & 51461 & Reference & Reference \\
\hline Yes & 7939 & $1.02(1.00$ to 1.04$)$ & 0.99 (0.97 to 1.02$)$ \\
\hline
\end{tabular}

urinary albumin is part of the performance index in the NICE QOF, it is anticipated that the majority of the study population would have data on renal monitoring during the study period. Therefore, the CPRD GOLD primary care database is well suited for this study. Despite this, this study has some limitations. First, some laboratory data might not be recorded in the database. In the UK, the GP could enter the laboratory values in three ways: (1) enter them directly in the laboratory value field; (2) add a comment to the computer system with the laboratory value; (3) attach a pdf file with the laboratory data. Laboratory values entered with a GP's comment or in an attached pdf file are not captured in the CPRD research databases. The percentage of patients who had a test within 1 year after initiation of antidiabetic drug therapy could be higher than what we observed $(75.6 \%)$. Second, the CPRD laboratory data have the following limitations: (1) there were a range of laboratory tests available. It was not always possible to tell which test was used. (2) It was not always clear which laboratory units $(\mathrm{mg} / \mathrm{L}, \mathrm{mmol} / \mathrm{L}, \mathrm{mg} / \mathrm{d}$, data not entered) were used. (3) Sometimes there were mismatches between MedCode and Enttype in the laboratory file, so it was not clear which test the data referred to. Where the data were not clear, we set the laboratory results as unknown. (4) The results for tests undertaken in the urology clinics might not be recorded in the CPRD. Finally, we did not assess the monitoring by ethnicity. Study findings from this study can be well generalizable to the UK T2DM patient population aged 40 years or older but may not be generalizable to other countries in the world with a different ethnicity distribution or a different healthcare system.

In a nationally representative sample of the UK T2DM patient population aged 40 years or older, we demonstrated that proteinuria monitoring in T2DM population was suboptimally compliant with the UK NICE guideline and was independently associated with age, gender, smoking status, and year of cohort entry. It decreased with time since start of diabetic drug therapy and with number of treatment changes. Given the importance of prevention of kidney disease progression, future studies should assess the rate of renal function decline among patients with T2DM and examine whether the renal function would get better among those patients who receive proteinuria screening following the guideline. 
Key research questions:

- Among patients with T2DM who receive routine proteinuria monitoring, what is their renal functions decline rate?

- Will renal functions of patients with T2DM who receive routine proteinuria screening get any better?

- Are there significant differences in physicians' management of patients with T2DM if some patients' renal functions improve while others' deteriorate?

Acknowledgements The authors would like to acknowledge Dr Ali Hariri, Dr Stephanie Moran (Takeda Development Center Americas, Inc.), and Dr Gunnar Johansson (Uppsala University, Sweden) for their medical input and Dr Baoguo Jiang (Takeda Development Center Americas, Inc.) for validation of data analysis.

Contributors PD developed the primary study concept and participated in the study design, application for protocol approval by the CPRD ISAC, data analysis, and overall coordination of the project personnel. HL participated in the study design, application for protocol approval by the CPRD ISAC, data analysis, and drafting of the manuscript. CK contributed to the study design, data acquisition, and data analysis. SM contributed to data acquisition, data cleaning, and data analysis. JHLL contributed to data analysis including Cox regression. All authors contributed to data interpretation, critical revision for important intellectual content, and final approval of the manuscript. HL, CK, and PD are the guarantors of this work and had full access to all the data in the study and take responsibility for the integrity of the data and the accuracy of the data analysis.

Funding This study was supported by the Takeda Pharmaceuticals. All authors are employees of Takeda at the time of the study.

Competing interests All authors were employees of Takeda at the time of the study.

Ethics approval CPRD Independent Scientific Advisory Committee (ISAC) for Medicines \& Healthcare products Regulatory Agency (MHRA) Database Research.

Provenance and peer review Not commissioned; externally peer reviewed.

Data sharing statement The authors state that any additional unpublished data from the study, if any, are available to readers in electronic formats, given the provisions of the data license contract between Takeda and the UK CPRD are satisfied.

Open Access This is an Open Access article distributed in accordance with the Creative Commons Attribution Non Commercial (CC BY-NC 4.0) license, which permits others to distribute, remix, adapt, build upon this work noncommercially, and license their derivative works on different terms, provided the original work is properly cited and the use is non-commercial. See: http:// creativecommons.org/licenses/by-nc/4.0/
REFERENCES

1. Neugarten J, Acharya A, Silbiger SR. Effect of gender on the progression of nondiabetic renal disease: a meta-analysis. J Am Soc Nephrol 2000;11:319-29.

2. Nzerue CM, Demissochew H, Tucker JK. Race and kidney disease: role of social and environmental factors. J Natl Med Assoc 2002;94 (8 Suppl):28S-38S.

3. Gambaro G, Bax G, Fusaro M, et al. Cigarette smoking is a risk factor for nephropathy and its progression in type 2 diabetes mellitus. Diabetes Nutr Metab 2001;14:337-42.

4. Bailey CJ, Day C. Diabetes therapies in renal impairment. Br J Diab Vasc Dis 2012:12:167-71.

5. National Institute for Health and Clinical Excellence. Type 2 diabetes: newer agents for blood glucose control in type 2 diabetes. Royal College of Physicians, 2009.

6. Viswanathan G, Upadhyay A. Assessment of proteinuria. Adv Chronic Kidney Dis 2011;18:243-8.

7. National Collaborating Centre for Chronic Conditions. Type 2 diabetes: national clinical guideline for management in primary and secondary care (update). Royal College of Physicians, 2008.

8. Management of diabetes. Scottish Intercollegiate Guidelines Network-SIGN March 2010.

9. Levin A, Stevens PE, Bilous RW, et al., Kidney disease: Improving global outcomes (KDIGO) CKD work group. KDIGO 2012 clinical practice guideline for the evaluation and management of chronic kidney disease. Kidney Int Supp/ 2013;3:1-150.

10. de Jong PE, Curhan GC. Screening, monitoring, and treatment of albuminuria: public health perspectives. J Am Soc Nephrol 2006;17:2120-6.

11. Miettinen $\mathrm{H}$, Haffner SM, Lehto $\mathrm{S}$, et al. Proteinuria predicts stroke and other atherosclerotic vascular disease events in nondiabetic and non-insulin-dependent diabetic subjects. Stroke 1996;27:2033-9.

12. Recorded disease, prevalence, achievements and exceptions. Quality and Outcomes Framework (QOF) for April 2013-March 2014. England: Health \& Social Care Information Centre, 2014.

13. Barrett A, Cronin H, Hickey A, et al. Fifty plus in Ireland 2011: first results from The Irish Longitudinal Study on Ageing (TILDA). Trinity College Dublin, 2011.

14. Biesenbach $\mathrm{G}$, Grafinger $\mathrm{P}$, Janko $\mathrm{O}$, et al. Influence of cigarettesmoking on the progression of clinical diabetic nephropathy in type 2 diabetic patients. Clin Nephrol 1997;48:146-50.

15. Chuahirun T, Wesson DE. Cigarette smoking predicts faster progression of type 2 established diabetic nephropathy despite ACE inhibition. Am J Kidney Dis 2002;39:376-82.

16. Kahende JW, Adhikari B, Maurice E, et al. Disparities in health care utilization by smoking status-NHANES 1999-2004. Int J Environ Res Public Health 2009;6:1095-106.

17. Mayer G., Group TIPS. Results from the TIP (Tritace in Proteinuria) intensified monitoring project. Kidney Blood Press Res 2002;25:80-6.

18. de Zeeuw D, Remuzzi G, Parving HH, et al. Proteinuria, a target for renoprotection in patients with type 2 diabetic nephropathy: lessons from RENAAL. Kidney Int 2004;65:2309-20.

19. Turner R. Intensive blood-glucose control with sulphonylureas or insulin compared with conventional treatment and risk of complications in patients with type 2 diabetes (UKPDS 33). Lancet 1998;352:837-53. 